\title{
Pelaksanaan Pola Pemuridan KAMBIUM dalam Memberikan Keyakinan Keselamatan Anak Usia 13 - 18 Tahun
}

\author{
Frets Keriapy \\ Sekolah Tinggi Agama Kristen Terpadu Pesat Salatiga \\ fretskeriapy1106@gmail.com
}

\begin{abstract}
Abstrak
Pemuridan merupakan tugas orang Kristen siapa pun dia. Hal ini merupakan keharusan murid Yesus. Sebelum Yesus naik ke Surga, Ia memberikan pesan terakhir kepada para murid-Nya untuk melakukan menjadi segala bangsa muridNya. Dalam Penelitian ini, proses pemuridan yang dipakai adalah pemuridan dengan menggunakan pola KAMBIUM. KAMBIUM merupakan satu pola pemuridan yang digunakan oleh PESAT Maluku Utara dalam melakukan pemuridan. Metode yang digunan dalam karya ilmiah ini adalah dengan menggunakan metode kualitatif dengan pengumpulan data menggunakan wawancara dan observasi. Hasil penelitian ini menunjukkan bahwa proses pemuridan pola KAMBIUM secara signifikan memberikan dampak pada keyakinan keselamatan pada Anak usia 13-18 tahun. Dampak yang dihasilkan adalah 22 anak pemuridan yang mengikuti kelas pemuridan, 19 di antaranya, meyakini akan keselamatannya dan meyakini bahwa keselamatan tidak bisa hilang.
\end{abstract}

\section{Kata Kunci: Pemuridan; Murid; Anak Usia 13-18 Tahun; Pola KAMBIUM}




\section{PENDAHULUAN}

Manusia merupakan makhluk yang diciptakan Allah menurut gambarNya. "Berdasarkan penafsiran Yahudi, ungkapan "gambar dan rupa Allah" harus dipahami "menurut patron yang dikehendaki Allah" atau "menurut apa yang dibayangkan Allah", di bagian lain dikatakan "Image of God" (citra Allah)" (Keriapy, 2019). Keistimewaan yang Allah berikan kepada manusia yang tidak diberikan-Nya kepada makhluk yang lain, menjadikan manusia sebagai wakil Allah di dunia. Abineno menjelaskan hal ini dengan jelas, yakni "kepada manusia, yang Allah ciptakan sebagai laki-laki dan perempuan menurut gambar-Nya - menurut kesaksian Alkitab - Allah memberikan kuasa kepada manusia untuk berkuasa atas makhluk hidup lainnya (Kej. 1:26 dan 28). Menurut nats ini manusia - sekalipun ia berasal dari tanah (adamah) dan sama seperti makhluk lain yang diciptakan Allah untuk mendiami bumi ini bersama-sama dengan mereka sama sekali berada di pihak Allah. Ia adalah "wakil-Nya" di bumi untuk berkuasa atas makhluk-makhluk yang lain" (Abineno, 2015). Selanjutnya Arifianto, dkk mengatakan dengan gamblang bahwa Allah yang begitu mengasihi manusia, memberikan nyawa-Nya demi penebusan (Arifianto et al., 2020).

Hal yang serupa pun dikatakan oleh James Montgomery Boice mengenai gambar Allah, " perempuan dan laki-laki memiliki atribut-atribut kepribadian yang Allah sendiri miliki, tetapi yang binatangbinatang, tumbuh-tumbuhan dan materi tidak miliki"(Boice, 2015) Namun atributatribut dari Allah itu hilang dikarenakan dosa ketidaktaatan yang dilakukan oleh Adam dan Hawa yang mengakibatkan semua manusia tanpa terkecuali jatuh ke dalam dosa (Sproul, 2014). Oleh karena itu, hal inilah yang mendasari bahwa manusia tidak dapat menyelamatkan dirinya sendiri, selain dari Allah sendiri yang berinisiatif untuk melakukan karya penyelamatan, sehingga Allah mengutus Anak-Nya (Yesus Kristus) ke dalam dunia untuk menebus dosa umat manusia seutuhnya (tubuh, jiwa dan roh). Namun demikian, tugas tersebut perlu untuk ditanggapi juga oleh umat percaya yakni di dalamnya juga gereja perlu untuk berperan aktif dalam menanggapi perintah ini, untuk melakukan Amanat Agung yang Yesus berikan kepada murid-Nya sebelum Ia naik ke Surga (Matius 28:19-20). Amanat Agung tidak berhenti pada percaya kepada Yesus, melainkan terus berlanjut sehingga mengalami pertumbuhan (Sugiono, 2008).

Namun, jika dilihat gereja masa kini sedang menghadapi suatu permasalahan yang sangat serius. Di samping gereja sering kali dipakai oleh oknum tertentu sebagai kendaraan politik, (Tampenawas, 2020) gereja Tuhan yang seharusnya menjadi saksi, tidak dapat berbuat banyak bahkan seakan terlena dengan kemajuan teknologi yang jika tidak disikapi dengan baik dapat merusak generasi muda gereja yang notabene adalah tulang punggung gereja itu sendiri. William Temple mengatakan bahwa " kekristenan adalah agama yang paling material dari semua agama. Tetapi kekristenan bukanlah materialistik" (Stott, 2012). Selain kemajuan teknologi yang membuat gereja terlena sehingga melupakan tugas utama gereja untuk menjadi saksi, adalah kegiataan keagamaan yang sudah menjadi rutinitas.

Bambang Budijanto mengatakan bahwa "Gereja (Ecclesia) sebagai komunitas Kerajaan yang dinamis telah dikurangi menjadi kegiatan keagamaan sekali seminggu. Tingkat kegiatan anggota jemaat menyusut dari tujuh hari seminggu menjadi hanya kegiatan ibadah rutin minggu pagi. Hal ini, secara signifikan 
telah mengurangi kesempatan anggotanya bertumbuh dalam perjalanan hidup mereka untuk menjadi murid" (Bambang, 2009). Oleh karenanya, generasi muda lebih memilih bergaul dengan dunia daripada berada di dalam gereja karena sudah terbuai oleh kenikmatan dunia. Gereja seakan melupakan tugas dan tanggung jawabnya sebagaimana Amanat Agung Yesus Kristus, sesaat sebelum Ia terangkat ke Sorga, yakni membaptis (baptizo) (Bambang, 2009), mengajar (didasko) (Bambang, 2009) dan yang paling penting adalah menjadikan seluruh bangsa muridNya (Matius 28:18-20). Selain itu, tugas gereja dipanggil untuk bisa membebaskan manusia dari segala belenggu yang mengikat manusia (Benyamin \& Gratia, 2020).

Kehidupan kekristenan masyarakat desa Goal, belum menunjukkan nilai-nilai kristiani yang signifikan meskipun penduduknya $99 \%$ beragama Kristen (Diambil dari dokumen desa tahun 2019). Kehidupan masyarakat di desa ini masih terlibat dengan berbagai macam persoalan, yakni perselingkuhan, pesta pora, mabuk-mabukan dan bahkan anakanak sudah merokok. Melihat adanya kesempatan untuk melaksanakan pemuridan dengan jumlah anak-anak usia 13-18 tahun sebanyak 26 anak yang terdiri dari laki-laki dan perempuan, maka tim PESAT Maluku Utara mengambil sebuah langkah untuk membangun generasi baru melalui kelompok pemuridan. Konsep generasi baru yang penulis maksudkan ialah suatu generasi yang berakar, bertumbuh dan berbuah di dalam Kristus, serta memiliki memiliki karakter Kristus. Dengan memiliki kepribadian yang sesuai dengan kebenaran Firman Tuhan, maka niscaya ke depan generasi tersebut akan menjadi pemimpin bangsa yang takut akan Tuhan. Hal inilah yang terus memotivasi tim PESAT cabang Malukut Utara dalam membina anak-anak usia 13-18 tahun yang ada di desa Goal melalui kelompok Pemuridan dengan menggunakan pola pemuridan KAMBIUM. Mengingat pelaksanaan kelompok pemuridan (kelompok pemuridan gabungan pemudaremaja GMIH Diaspora Goal dan GKPMI Eden Goal) ini telah berjalan \pm 1 tahun, maka penting untuk melakukan suatu pengamatan sehingga dapat mengetahui seberapa jauh dampak pelaksanaan kelompok pemuridan pola KAMBIUM terhadap anak dilihat dari keyakinan akan keselamatan yang Allah berikan secara cuma-cuma bagi seluruh orang percaya, terlebih khusus yang terjadi dalam diri anak pemuridan yang untuk kemudian hari menjadi bahan evaluasi baik bagi tim PESAT cabang Maluku Utara sebagai pemurid maupun bagi peserta kelompok pemuridan serta komunitas KAMBIUM.

\section{METODE PENELITIAN}

Menurut Sugiyono metode penelitian kualitatif sering disebut metode penelitian naturalistik karena penelitiannya dilakukan pada kondisi yang alamiah (natural setting) sesuai dengan fakta yang ada (Sugiyono, 2014) Selanjutnya ia mengatakan bahwa, metode penelitian kualitatif adalah metode yang lebih mengarah pada filsafat postpositivisme, yang selanjutnya dipakai untuk meneliti pada sebuah situasi obyek alamiah, (sebagai lawannya adalah eksperimen) dimana peneliti adalah sebagai instrumen kunci, teknik pengumpulan data dilakukan secara triangulasi (gabungan), analisis data bersifat induktif/deduktif (Sugiyono, 2014). Menurut Strauss dan Corbin mengatakan bahwa, penelitian kualitatif sebagai jenis penelitian yang temuan-temuannya tidak diperoleh melalui prosedur statistik atau penghitungan lainnya, sehingga berbeda dengan penelitian kuantitatif (Strauss \& Corbin, 2003) Selanjutnya, menurut 
Bogdan dan Taylor mendefinisikan metodologi kualitatif sebagai prosedur penelitian yang menghasilkan data deskriptif berupa kata-kata tertulis atau lisan dari objek atau subjek penelitian serta perilaku dari subjek yang akan diteliti (Moleong, 2011). Selanjutnya, Moleong mendefinisikan penelitian kualitatif sebagai penelitian yang bertujuan untuk mendapatkan informasi dari fenomena yang dialami oleh subjek penelitian (Moleong, 2011).

Dilihat dari pandangan para ahli di atas, maka penelitian kualitatif ini berguna untuk membantu menjawab akan kebutuhan esensial dari orang kristen mengenai keyakinan keselamatannya, terlebih khusus kebutuhan kerohanian anak pemuridan yang dilaksanakan oleh tim PESAT cabang Maluku Utara, tepatnya di GKPMI Eden Goal. Dalam penulisan karya ilmiah ini, diharapkan dapat membantu, dalam hal memahami seberapa besar keyakinan yang dimiliki oleh anak yang dimuridkan dalam kelompok pemuridan pola KAMBIUM. Oleh karena itu, dalam penelitian ini akan menggunakan pengambilan data yang natural (alami) yang akan dirangkai dengan kata-kata dan bukan dengan angka.

\section{PEMBAHASAN}

\section{Pemuridan Pola KAMBIUM}

KAMBIUM merupakan singkatan dari komunitas pertumbuhan iman untuk menjadi murid Kristus, yang dirancang untuk menolong orang yang dibina menanggapi panggilan Kristus ini sebagai sebuah pendekatan pembelajaran (KAMBIUM, Berakar Dalam Kristus, 2016, p. 6). Dalam melakukan suatu kegiatan akan tidak berguna jika tidak terlihat hasil akhir dari pada suatu kegiatan tersebut. Oleh karena itu, untuk melihat efektifitasnya, maka ada dua kategori yang di ajarkan dalam pola pemuridan KAMBIUM khususnya dalam hal jaminan keselamatan, yakni:

A. Sikap Tuhan terhadap umatnya.

Dalam membahas materi ini, ada ayat-ayat Firman Tuhan yang diberikan seperti dalam Yohanes 10:27-30, Yohanes 1:12, Yohanes 5:24 dan 1Yohanes 5:11-13. Ayat-ayat ini menjelaskan bahwa ketika manusia percaya kepada Yesus sebagai Tuhan dan juruselamat, maka mereka telah menjadi anak Allah. Menjadi anak Allah berarti Allah mengenal mereka dan demikian pula mereka mengenai Allah. Di samping itu, ketika seseorang menjadi percaya, maka hidup kekal itu diberikan kepadanya. Kekal berarti tidak memiliki batas waktu. Allah mengaruniakan hidup yang kekal dan hidup kekal itu hanya ada di dalam anak-Nya, yaitu Yesus Kristus.

Louis Berkhof mendefinsikan kata metanoia sebagai 1) mengetahui sesudahnya; pengetahuan yang diperoleh kemudian; 2) berubah pikiran sebagai hasil dari pengetahuan yang diperoleh itu; 3) dalam kaitan dengan perbuhan dalam pikiran ini, berarti menyesali jalan yang semula diambil; dan 4) suatu tingkah laku untuk masa depan, yang terpancar dari apa yang sudah mendahului (Berkhof, 2014). Kasih yang begitu besar dari Allah kepada umat-Nya melalui Yesus Kristus menjadikan anugerah yang diberikan oleh Allah menjadi mahal. Kasih yang begitu besar ini, menjadikan umat-Nya melekat kepada Allah dan tidak ada satu pun yang dapat memisahkan manusia dari pada kasih Allah kepada umat-Nya (Roma 8:35). Karena kasih Allah yang begitu besar, maka umat yang percaya kepadanya dilahirkan kembali oleh kebangkitan Kristus dari antara orang mati kepada suatu hidup yang penuh pengharapan untuk menerima suatu bagian yang tidak dapat binasa serta terpelihara karena iman yang 
Allah berikan. Demikian juga setalah Yesus ke Surga, Ia menjanjikan akan mengirimkan Roh Kudus untuk menolong, menuntun, memimpin dan Roh Kudus tersebutlah yang merupakan jaminan umat percaya yang menjadikan umat kepunyaan Allah (1Petrus 1:3-5 dan Efesus 1:13-14).

Oleh karena itu, jaminan keselamatan yang Allah berikan tidak terlepas dari pada sikap Allah kepada umatNya. Sikap Allah inilah yang menentukan akan anugerah keselamatan yang diberikan kepada manusia secara cuma-cuma. Sikap Allah ini, menjadikan manusia yang percaya kepada Allah sebagai anak-Nya. Oleh karena kelompok peserta pemuridan berusia 13-18 tahun, maka ayat-ayat di atas adalah ayat-ayat yang harus dihafal oleh peserta pemuridan agar mereka mengerti dan memahami bahwa anugerah Allah besar bagi umat pilihan-Nya. Hal ini penting supaya membantu mereka untuk tetap teguh percaya kepada Kristus sebagai Tuhan dan Juruselamat ketika mereka diperhadapkan dengan situasi yang dapat membawa mereka untuk meninggalkan Tuhan.

\section{B. Faktor penggoyah keyakinan keselamatan}

Ada tiga faktor yang dapat menggoyah akan keyakinan keselamatan umat manusia dalam pelajaran KAMBIUM, yakni faktor Iblis, faktor perbuatan dan faktor bukan anak.

\section{Faktor Iblis.}

Alkitab mencatat dalam 1 Petrus 5:89 "sadarlah dan berjaga-jagalah! Lawanmu, si Iblis, berjalan keliling sama seperti singa yang mengaum-aum dan mencari orang yang dapat di telannya. Lawanlah dia dengan iman yang teguh, sebab kamu tahu, bahwa semua saudaramu di seluruh dunia menanggung penderitaan yang sama." Pekerjaan Iblis adalah untuk membuat anak-anak Tuhan jatuh ke dalam dosa. Iblis tidak akan pernah berhenti bekerja sampai apa yang ia inginkan tercapai. Keinginan Iblis yang begitu besar ini, menjadikan manusia sering tergoda untuk jatuh ke dalam perangkap yang dibuatnya. Penderitaan, penindasan, ketidakadilan yang terjadi di dunia ini kepada seluruh umat manusia merupakan salah satu pekerjaan Iblis agar supaya anak-anak Tuhan meninggalkan Tuhan. Alkitab jelas mencatat bahwa "lawanlah dia dengan iman yang teguh". Manusia yang jatuh ke dalam perangkap dari pada Iblis, dikarenakan tidak berakar kuat dalam Tuhan dengan kata lain tidak memiliki iman yang kokoh. Fakta kepastian keselamatan dijamin oleh Tuhan dan firman-Nya, bukan oleh perasaan dan keyakinan sendiri.

\section{Faktor perbuatan}

Alkitab mencatat dalam Yesaya 59:12, "Sesungguhnya, tangan Tuhan tidak kurang panjang untuk menyelamatkan, dan pendengaran-Nya tidak kurang tajam untuk mendengar; tetapi yang merupakan pemisah antara kamu dan Allahmu ialah segala kejahatanmu, dan yang membuat Dia menyembunyikan diri terhadap kamu, sehingga ia tidak mendengar, ialah segala dosamu." Yesaya jelas mengatakan bahwa yang membuat manusia terpisah dengan Allah adalah dosa. Dosa menjadikan manusia melawan kehendak Allah. Faktor perbuatan ini yang selalu menghantui manusia dengan memiliki perasaan tidak layak untuk menjadi anak Allah. Namun Alkitab juga memberikan solusi yang baik dari segala perbuatan jahat yang pernah dilakukan yaitu mengaku dosa di hadapan Tuhan dan berbalik kepada jalannya Tuhan (1Yohanes 1:9).

\section{Faktor bukan anak}

Faktor yang terakhir sering mengintimidasi umat Allah dengan mengatakan bahwa tidak ada satu pun manusia yang sempurna sehingga dapat menjadi Anak Allah. Paulus pernah 
berkata kepada jemaat di Roma dalam Roma 8:15-16 bahwa "Sebab kamu tidak menerima roh perbudakan yang membuat kamu menjadi takut lagi, tetapi kamu telah menerima Roh yang mennjadikan kamu anak Allah. Oleh Roh itu kita beseru: "ya, Abba, ya Bapa!"

Dalam hal keyakinan keselamatan, seseorang dapat tergolong ke dalam salah satu dari tiga kelompok, yaitu:(Buku Peserta Berakar Dalam Kristus, 2011, p. 21)

a. Orang yang yakin akan keselamatannya

b. Orang yang kadang yakin dan ragu akan keselamatanya

c. Orang yang mengharapkan dirinya diselamatkan namun tidak tahu pasti

Dalam pemahaman anggota pemuridan mengenai dua kategori yang diajarkan dalam jaminan keselamatan dalam pola berakar yaitu mengenai sikap Tuhan terhadap umat-Nya dan faktor-faktor yang dapat menggoyahkan keyakinan keselamatan dapat dipahami oleh 19 anak pemuridan dengan percaya kepada Tuhan Yesus sebagai Tuhan dan Juru Selamat maka dengan demikian telah menjadi anakanak Allah namun 3 anak pemuridan masih berpegang pada keselamatan lewat perbuatan. ${ }^{1}$ Menurut FM sebagai penanggung jawab kelompok pemuridan mengatakan bahwa, ada 19 anak yang telah memiliki keyakinan keselamatan dan 3 anak pemuridan yang kadang meyakini dan kadang meragukan keselamatannya. ${ }^{2}$

HASIL

$\begin{array}{lcc}\text { Pelaksanaan } & \text { Pola } & \text { Pemuridan } \\ \text { KAMBIUM } & \text { Terhadap } & \text { Keyakinan } \\ \text { Keselamatan Anak } & \end{array}$

\footnotetext{
${ }^{1}$ Dari hasil wawancara tidak terstruktur, 3 anak anggota pemuridan menjawab pertanyaan "Bagaimana mendapatkan keselamatan? Dengan
}

Sejak kehadiran tim PESAT dalam melaksanakan kelompok pemuridan memiliki pengaruh yang besar terhadap anak-anak yang mengikuti kelompok pemuridan setiap hari minggu di GKPMI Eden Goal. Hasil yang didapat berdasarkan fakta yang penulis dapat dari berbagai data yang penulis kumpulkan dengan memakai berbagai alat pengumpulan data (HP/ Hand Phone untuk merekam wawancara dengan nara sumber yang ada dan catatan kegiatan yang penulis miliki untuk mencatat hal-hal yang penting). Tujuan diadakan kegiatan ini adalah untuk menjadikan generasi muda menjadi murid Kristus yang radikal yang berakar dalam Kristus sehingga apabila suatu saat nanti mereka diperhadapkan dengan hal-hal yang dapat membuat mereka untuk meninggalkan Tuhan, hal-hal tersebut tidak mudah mempengaruhi mereka.

Dari 22 anak yang mengikuti kelompok pemuridan, sebagian besar yakni 19 anak dari mereka telah yakin akan anugerah keselamatan yang telah diberikan Kristus kepada manusia dan tidak didapatkan karena perbuatan baik manusia dan tiga orang anak yang masih ragu dikarenakan daya tangkap terhadap materi yang diberikan tergolong lamban dan juga karena faktor kehadiran di mana mereka tidak selalu mengikuti dalam setiap materi. Untuk tingkat keaktifan dalam mengikuti kelompok pemuridan, anak-anak begitu antusias dalam mengikuti setiap materi yang ada setiap hari minggu. Ada 19 anak yang selalu hadir dalam setiap materi yang diberikan dalam pola berakar dalam KAMBIUM dan tiga orang tidak mengikuti 10 materi dalam pola berakar. Untuk lebih jelas, dapat lihat tabel dibawah ini:

menjawab menerima keselamatan lewat rajin beribadah, beroda dan menolong.

${ }^{2}$ Hasil wawancara dengan FM, 28 Mei 2017 
Tabel 1.

Efektifitas Pemuridan Pola KAMBIUM

\begin{tabular}{|c|c|c|c|}
\hline No & Nama & $\begin{array}{c}\text { Sebelum mengikuti } \\
\text { pemuridan }\end{array}$ & $\begin{array}{c}\text { Setelah mengikuti } \\
\text { pemuridan }\end{array}$ \\
\hline 1 & NB & $\begin{array}{l}\text { Keselamatan bisa hilang dan } \\
\text { ditentukan oleh perbuatan } \\
\text { baik yang dilakukan manusia } \\
\text { selama hidup }\end{array}$ & $\begin{array}{lr}\text { Meyakini } & \text { akan } \\
\text { keselamatan } & \text { yang } \\
\text { diterima tidak } & \text { akan } \\
\text { hilang dan } & \text { tidak } \\
\text { didapatkan } & \text { dari } \\
\text { perbuatan manusia } \\
\text { selama di dunia. }\end{array}$ \\
\hline 2 & $\mathrm{DA}$ & $\begin{array}{l}\text { Keselamatan bisa hilang dan } \\
\text { ditentukan oleh perbuatan } \\
\text { baik yang dilakukan manusia } \\
\text { selama hidup }\end{array}$ & $\begin{array}{lr}\text { Meyakini } & \text { akan } \\
\text { keselamatan } & \text { yang } \\
\text { diterima tidak } & \text { akan } \\
\text { hilang dan } & \text { tidak } \\
\text { didapatkan } & \text { dari } \\
\text { perbuatan manusia } \\
\text { selama di dunia. }\end{array}$ \\
\hline 3 & MT & $\begin{array}{l}\text { Keselamatan bisa hilang dan } \\
\text { ditentukan oleh perbuatan } \\
\text { baik yang dilakukan manusia } \\
\text { selama hidup }\end{array}$ & $\begin{array}{lr}\text { Meyakini } & \text { akan } \\
\text { keselamatan } & \text { yang } \\
\text { diterima tidak } & \text { akan } \\
\text { hilang dan } & \text { tidak } \\
\text { didapatkan } & \text { dari } \\
\text { perbuatan manusia } & \\
\text { selama di dunia. } & \end{array}$ \\
\hline 4 & FT & $\begin{array}{l}\text { Keselamatan bisa hilang dan } \\
\text { ditentukan oleh perbuatan } \\
\text { baik yang dilakukan manusia } \\
\text { selama hidup }\end{array}$ & $\begin{array}{lr}\text { Meyakini } & \text { akan } \\
\text { keselamatan } & \text { yang } \\
\text { diterima tidak } & \text { akan } \\
\text { hilang dan } & \text { tidak } \\
\text { didapatkan } & \text { dari } \\
\text { perbuatan manusia } & \\
\text { selama di dunia. } & \end{array}$ \\
\hline 5 & $S$ & $\begin{array}{l}\text { Keselamatan bisa hilang dan } \\
\text { ditentukan oleh perbuatan } \\
\text { baik yang dilakukan manusia } \\
\text { selama hidup }\end{array}$ & $\begin{array}{lr}\text { Meyakini } & \text { akan } \\
\text { keselamatan } & \text { yang } \\
\text { diterima tidak } & \text { akan } \\
\text { hilang dan } & \text { tidak } \\
\text { didapatkan } & \text { dari } \\
\text { perbuatan manusia } \\
\text { selama di dunia. }\end{array}$ \\
\hline 6 & VT & $\begin{array}{l}\text { Keselamatan bisa hilang dan } \\
\text { ditentukan oleh perbuatan } \\
\text { baik yang dilakukan manusia } \\
\text { selama hidup }\end{array}$ & $\begin{array}{lr}\text { Meyakini } & \text { akan } \\
\text { keselamatan } & \text { yang } \\
\text { diterima tidak } & \text { akan } \\
\text { hilang dan } & \text { tidak } \\
\text { didapatkan } & \text { dari } \\
\text { perbuatan manusia } \\
\text { selama di dunia. }\end{array}$ \\
\hline
\end{tabular}




\begin{tabular}{|c|c|c|c|}
\hline 7 & HB & $\begin{array}{l}\text { Keselamatan bisa hilang dan } \\
\text { ditentukan oleh perbuatan } \\
\text { baik yang dilakukan manusia } \\
\text { selama hidup }\end{array}$ & $\begin{array}{lr}\text { Meyakini } & \text { akan } \\
\text { keselamatan } & \text { yang } \\
\text { diterima tidak } & \text { akan } \\
\text { hilang dan } & \text { tidak } \\
\text { didapatkan } & \text { dari } \\
\text { perbuatan manusia } & \\
\text { selama di dunia. } & \end{array}$ \\
\hline 8 & $\mathrm{CB}$ & $\begin{array}{l}\text { Keselamatan bisa hilang dan } \\
\text { ditentukan oleh perbuatan } \\
\text { baik yang dilakukan manusia } \\
\text { selama hidup }\end{array}$ & $\begin{array}{lr}\text { Meyakini } & \text { akan } \\
\text { keselamatan } & \text { yang } \\
\text { diterima tidak } & \text { akan } \\
\text { hilang dan } & \text { tidak } \\
\text { didapatkan } & \text { dari } \\
\text { perbuatan manusia } & \\
\text { selama di dunia. } & \end{array}$ \\
\hline 9 & $\mathrm{DB}$ & $\begin{array}{l}\text { Keselamatan bisa hilang dan } \\
\text { ditentukan oleh perbuatan } \\
\text { baik yang dilakukan manusia } \\
\text { selama hidup }\end{array}$ & $\begin{array}{lr}\text { Meyakini } & \text { akan } \\
\text { keselamatan } & \text { yang } \\
\text { diterima tidak } & \text { akan } \\
\text { hilang dan } & \text { tidak } \\
\text { didapatkan } & \text { dari } \\
\text { perbuatan manusia } & \\
\text { selama di dunia. } & \end{array}$ \\
\hline 10 & FB & $\begin{array}{l}\text { Keselamatan bisa hilang dan } \\
\text { ditentukan oleh perbuatan } \\
\text { baik yang dilakukan manusia } \\
\text { selama hidup }\end{array}$ & $\begin{array}{lr}\text { Meyakini } & \text { akan } \\
\text { keselamatan } & \text { yang } \\
\text { diterima tidak } & \text { akan } \\
\text { hilang dan } & \text { tidak } \\
\text { didapatkan } & \text { dari } \\
\text { perbuatan } & \text { manusia } \\
\text { selama di dunia. } & \end{array}$ \\
\hline 11 & MB & $\begin{array}{l}\text { Keselamatan bisa hilang dan } \\
\text { ditentukan oleh perbuatan } \\
\text { baik yang dilakukan manusia } \\
\text { selama hidup }\end{array}$ & $\begin{array}{lr}\text { Meyakini } & \text { akan } \\
\text { keselamatan } & \text { yang } \\
\text { diterima tidak } & \text { akan } \\
\text { hilang dan } & \text { tidak } \\
\text { didapatkan } & \text { dari } \\
\text { perbuatan } & \text { manusia } \\
\text { selama di dunia. } & \end{array}$ \\
\hline 12 & $\mathrm{RB}$ & $\begin{array}{l}\text { Keselamatan bisa hilang dan } \\
\text { ditentukan oleh perbuatan } \\
\text { baik yang dilakukan manusia } \\
\text { selama hidup }\end{array}$ & $\begin{array}{lr}\text { Meyakini } & \text { akan } \\
\text { keselamatan } & \text { yang } \\
\text { diterima tidak } & \text { akan } \\
\text { hilang dan } & \text { tidak } \\
\text { didapatkan } & \text { dari } \\
\text { perbuatan manusia } & \\
\text { selama di dunia. } & \end{array}$ \\
\hline 13 & $\mathrm{OB}$ & $\begin{array}{l}\text { Keselamatan bisa hilang dan } \\
\text { ditentukan oleh perbuatan } \\
\text { baik yang dilakukan manusia } \\
\text { selama hidup }\end{array}$ & $\begin{array}{lr}\text { Meyakini } & \text { akan } \\
\text { keselamatan } & \text { yang } \\
\text { diterima tidak } & \text { akan } \\
\text { hilang dan } & \text { tidak } \\
\text { didapatkan } & \text { dari } \\
\text { perbuatan } & \text { manusia } \\
\text { selama di dunia. } & \end{array}$ \\
\hline
\end{tabular}




\begin{tabular}{|c|c|c|c|}
\hline 14 & $\mathrm{TT}$ & $\begin{array}{l}\text { Keselamatan bisa hilang dan } \\
\text { ditentukan oleh perbuatan } \\
\text { baik yang dilakukan manusia } \\
\text { selama hidup }\end{array}$ & $\begin{array}{lr}\text { Meyakini } & \text { akan } \\
\text { keselamatan } & \text { yang } \\
\text { diterima tidak } & \text { akan } \\
\text { hilang dan } & \text { tidak } \\
\text { didapatkan } & \text { dari } \\
\text { perbuatan manusia } & \\
\text { selama di dunia. } & \end{array}$ \\
\hline 15 & RHT & $\begin{array}{l}\text { Keselamatan bisa hilang dan } \\
\text { ditentukan oleh perbuatan } \\
\text { baik yang dilakukan manusia } \\
\text { selama hidup }\end{array}$ & $\begin{array}{l}\text { Keselamatan bisa hilang } \\
\text { dan ditentukan oleh } \\
\text { perbuatan baik yang } \\
\text { dilakukan manusia } \\
\text { selama hidup }\end{array}$ \\
\hline 16 & RO & $\begin{array}{l}\text { Keselamatan bisa hilang dan } \\
\text { ditentukan oleh perbuatan } \\
\text { baik yang dilakukan manusia } \\
\text { selama hidup }\end{array}$ & $\begin{array}{l}\text { Keselamatan bisa hilang } \\
\text { dan ditentukan oleh } \\
\text { perbuatan baik yang } \\
\text { dilakukan manusia } \\
\text { selama hidup }\end{array}$ \\
\hline 17 & IS & $\begin{array}{l}\text { Keselamatan bisa hilang dan } \\
\text { ditentukan oleh perbuatan } \\
\text { baik yang dilakukan manusia } \\
\text { selama hidup }\end{array}$ & $\begin{array}{lr}\text { Meyakini } & \text { akan } \\
\text { keselamatan } & \text { yang } \\
\text { diterima tidak } & \text { akan } \\
\text { hilang dan } & \text { tidak } \\
\text { didapatkan } & \text { dari } \\
\text { perbuatan manusia } \\
\text { selama di dunia. }\end{array}$ \\
\hline 18 & YL & $\begin{array}{l}\text { Keselamatan bisa hilang dan } \\
\text { ditentukan oleh perbuatan } \\
\text { baik yang dilakukan manusia } \\
\text { selama hidup }\end{array}$ & $\begin{array}{lr}\text { Meyakini } & \text { akan } \\
\text { keselamatan } & \text { yang } \\
\text { diterima tidak } & \text { akan } \\
\text { hilang dan } & \text { tidak } \\
\text { didapatkan } & \text { dari } \\
\text { perbuatan manusia } \\
\text { selama di dunia. }\end{array}$ \\
\hline 19 & MB & $\begin{array}{l}\text { Keselamatan bisa hilang dan } \\
\text { ditentukan oleh perbuatan } \\
\text { baik yang dilakukan manusia } \\
\text { selama hidup }\end{array}$ & $\begin{array}{lr}\text { Meyakini } & \text { akan } \\
\text { keselamatan } & \text { yang } \\
\text { diterima tidak } & \text { akan } \\
\text { hilang dan } & \text { tidak } \\
\text { didapatkan } & \text { dari } \\
\text { perbuatan manusia } \\
\text { selama di dunia. }\end{array}$ \\
\hline 20 & DN & $\begin{array}{l}\text { Keselamatan bisa hilang dan } \\
\text { ditentukan oleh perbuatan } \\
\text { baik yang dilakukan manusia } \\
\text { selama hidup }\end{array}$ & $\begin{array}{lr}\text { Meyakini } & \text { akan } \\
\text { keselamatan } & \text { yang } \\
\text { diterima tidak } & \text { akan } \\
\text { hilang dan } & \text { tidak } \\
\text { didapatkan } & \text { dari } \\
\text { perbuatan manusia } & \text { mama di dunia. }\end{array}$ \\
\hline 21 & YTT & $\begin{array}{l}\text { Keselamatan bisa hilang dan } \\
\text { ditentukan oleh perbuatan } \\
\text { baik yang dilakukan manusia } \\
\text { selama hidup }\end{array}$ & $\begin{array}{l}\text { Keselamatan bisa hilang } \\
\text { dan ditentukan oleh } \\
\text { perbuatan baik yang } \\
\text { dilakukan manusia } \\
\text { selama hidup }\end{array}$ \\
\hline
\end{tabular}


DIEGESIS: Jurnal Teologi

Volume 6 No. 1, Februari 2021 Hlm 36-48

45

\begin{tabular}{|c|l|l|lr|}
\hline 22 & HTT & Keselamatan bisa hilang dan & Meyakini & akan \\
& & ditentukan oleh perbuatan & keselamatan yang \\
& baik yang dilakukan manusia & diterima tidak akan \\
& selama hidup & hilang dan tidak \\
& & didapatkan dari \\
& & perbuatan manusia \\
& & & \\
& & &
\end{tabular}

Sumber: Sumber Primer dan diolah oleh Penulis 
Hasil yang begitu signifikan di mana konsep keselamatan anak pemuridan yang sebelumnya meyakini bahwa keselamatan diperoleh dengan rajin beribadah, berdoa dan melayani berubah menjadi keselamatan karena percaya. Menurut pernyataan oleh gembala GKPMI Eden Goal bahwa perubahan yang besar terjadi dalam diri anak-anak pemuridan setelah mengikuti kelompok pemuridan, dalam hal pergaulan ${ }^{3}$. Hal yang serupa pun dikatakan oleh FM, bahwa dengan melihat adanya pergaulan buruk yang terjadi di desa Goal, maka ia berusaha untuk bersinergi dengan gereja setempat untuk membuat kelompok pemuridan untuk anak muda. ${ }^{4}$ Dengan adanya kelompok pemuridan membantu gembala dalam mengembangkan kerohanian jemaat khususnya pemuda-pemudi yang ada di GKPMI Eden Goal. Tidak hanya untuk kemajuan kerohanian, melainkan juga untuk mengurangi tingkat kenakalan anak muda di desa Goal $^{5}$. Pengaruh yang diberikan dari hasil kelompok pemuridan membuat anak-anak pemuridan lebih tekun untuk berdiskusi tentang Firman Tuhan dengan sesama dan bahkan dengan gembala yang ada. Hasil dari pada kelompok pun menghasilkan dua orang pemuda yang melanjutkan sekolah ke STT (Sekolah Tinggi Teologi) Kalvary untuk mendalami akan Firman Tuhan. Kedua anak pemuridan itu adalah NB dan DA. ${ }^{6}$

${ }^{3}$ Pergaulan yang dimaksudkan adalah pergaulan buruk yang merusak kehidupan masa depan anak muda dalam hal mabukmabukan, perkelahian dan merokok.

${ }^{4}$ Hasil wawancara dengan FM, 28 Mei 2017

${ }^{6}$ Hasil wawancara dengan kedua orang tua dan NB dan DA, 29 Juni 2017
Dari hasil yang penulis peroleh selama melakukan penelitian terhadap kelompok pemuridan yang dilaksanakan di GKPMI Eden Goal, memberikan kontribusi yang positif terhadap 19 dari 22 anak-anak yang mengikuti kelompok pemuridan di mana cara pandang terhadap keyakinan keselamatan berdasarkan perbuatan baik dan ragu akan keselamatan yang Allah berikan dapat berubah kepada keselamatan yang semata Allah berikan dengan cuma-cuma tanpa membutuhkan andil (perbuatan baik) daripada manusia serta yakin akan keselamatan yang Allah anugerahkan kepada manusia.

Keyakinan keselamatan yang diyakini oleh anak pemuridan yang ada, dapat dilihat dari perubahan hidup yang terjadi dalam hidup mereka. Menurut kepala desa Goal mengatakan bahwa kenakalan anakanak yang ada di desa Goal disebabkan oleh karena keluarga yang tidak memperhatikan anak-anak mereka. $^{7}$ Hal inilah yang mendasari FM untuk membuat kelompok pemuridan di GKPMI Eden Goal. ${ }^{8}$ Menurut gembala GKPMI Eden, bahwa saat ini tidak ada anak muda GKPMI Eden Goal yang mabukmabukan serta terlibat dalam perkelahian ketika ada pesta yang

\footnotetext{
${ }^{7}$ Hasil wawancara dengan Kepala Desa Goal. 9 Mei 2017 Hal yang serupa pun dikatakan oleh FM sebagai penanggung jawab sekaligus penggerak kelompok pemuridan yang diadakan di GKPMI Eden Goal. 28 Mei 2017

${ }^{8}$ Hasil wawancara dengan FM, 28 Mei 2017
} 
diadakan di dalam desa. ${ }^{9}$ Hal yang serupa pun dikatakan dari orang tua anak pemuridan dimana mereka mengaku bahwa setelah diadakan pemuridan oleh tim PESAT di GKPMI Eden anak-anak mereka mengalami perubahan. Mereka yang sebelumnya keluar malam untuk mabuk-mabukan bersama temanteman kini sudah tidak lagi. ${ }^{10}$ Pengakuan salah satu dari pada peserta pemuridan, yakni NB bahwa yang mengubah paradigmanya mengenai jalan keselamatan dimana pandagannya sebelum mengikuti kelompok pemuridan dengan perbuatan baik dan berusaha dengan sedemikian rupa agar bisa berkenan di hadapan Tuhan untuk memperoleh keselamatan telah berubah menjadi keselamatan hanya melalui iman. ${ }^{11}$ Dalam buku. Dari perubahan ini menunjukkan bahwa materi yang diberikan dalam pemuridan dimana hidup harus selaras dengan kehendak Tuhan karena telah diselamatkan oleh karya penebusan Kristus di kayu salib dan menjadi saksi bagi sesama lewat perubahan hidup yang ditunjukkan.

\section{KESIMPULAN}

Setelah melakukan penelitian serta membahas hasil daripada penelitian dapat ditarik kesimpulan bahwa kelompok pemuridan yang dilakukan oleh tim PESAT cabang Maluku Utara di GKPMI Eden Goal memberikan efek yang begitu signifikan terhadap peserta dalam hal keyakinan keselamatan. Dengan pengajaran yang diberikan oleh

\footnotetext{
${ }^{9}$ Hasil wawancara dengan gembala GKPMI Eden Goal, 22 Mei 2017

${ }^{10}$ Hasil wawancara dengan orangtua dari TT, 4 Juni 2017
}

KAMBIUM membantu tim PESAT dan peserta pemuridan untuk dapat memahami dengan mudah isi materi yang diberikan. Setiap materi yang berikan kepada peserta kelompok pemuridan membantu para peserta untuk mengerti, memahami serta berusaha untuk hidup berpadanan dengan Firman Allah.

\section{DAFTAR PUSTAKA}

Abineno, J. L. C. (2015). Pokokpokok penting dari Iman Kristen. BPK Gunung Mulia.

Arifianto, Y. A., Triposa, R., \& Lembongan, P. K. (2020). Bible Study of Mission and Discipleship in the Great Commission and Its Implications for Today's Christian Life. Diegesis: Jurnal Teologi, 5(2), 25-42.

Bambang, B. (2009). No Plan B. ANDI.

Benyamin, P. I., \& Gratia, Y. P. (2020). Pengembangan Model Pendidikan Agama Kristen Bagi Anak Korban Kemiskinan. Ecodunamika, 3(1).

Berkhof, L. (2014). Teologi Sistematika Doktrin Keselamatan. Momentum.

Boice, J. M. (2015). Dasar-Dasar Iman Kristen. Surabaya: Momentum.

Buku Peserta Berakar Dalam Kristus. (2011). Perkantas.

KAMBIUM, Berakar dalam Kristus. (2016). Perkantas.

${ }^{11}$ Hasil wawancara dengan NB, Minggu 9 Juli 2017 
Keriapy, F. (2019). Spiritualitas Penderitaan Ayub Mempertanyakan Eksistensi Allah.

Moleong, L. J. (2011). Metodologi Penelitian Kualitatif, cetakan XXIX. Bandung: PT. Remaja, Rosdakarya.

Sproul, R. C. (2014). KebenaranKebenaran Dasar Iman Kristen. Malang: Seminari Alkitab Asia Tenggara.

Stott, J. (2012). Murid Yang Radikal. Perkantas.

Strauss, A., \& Corbin, J. (2003). Dasar-dasar penelitian kualitatif. Yogyakarta: Pustaka Pelajar.

Sugiono, S. (2008). PAK Dan Penginjilan Dalam Amanat Agung Yesus Kristus. Edukasi: Jurnal Pendidikan Agama Kristen, 1(1), 1-16.

Sugiyono. (2014). Metode Penelitian Pendidikan Pendekatan: Kualitatif, Kuantitatif dan $R \& D$. Alfabeta.

Tampenawas, A. R. (2020). Calvin's Ecclesiological View of Practical Politics in Church Service. THRONOS: Jurnal Teologi Kristen, 1(2), 115-127. 